\section{Entre o campo e} o laboratório: a dinâmica de produção de conhecimento no Ambulatório de Menopausa do Caism/ Unicamp

\section{Between the country and the laboratory: the dynamics of the production of knowledge at the Menopause Outpatients Clinic at Caism, Unicamp}

\author{
Rebeca Buzzo Feltrin \\ Pesquisadora colaboradora, Departamento de \\ Política Científica e Tecnológica/Instituto de Geociências/ \\ Universidade Estadual de Campinas. \\ Rua João Pandiá Calógeras, 51 \\ 13083-870 - Campinas - SP - Brasil \\ rebeca@ige.unicamp.br

\section{Lea Maria Leme Strini Velho} \\ Professora colaboradora, Departamento de \\ Política Científica e Tecnológica/Instituto de Geociências/ \\ Universidade Estadual de Campinas. \\ Rua João Pandiá Calógeras, 51 \\ 13083-870 - Campinas - SP - Brasil \\ velho@ige.unicamp.br
}

Recebido para publicação em julho de 2012.

Aprovado para publicação em junho de 2013.
FELTRIN, Rebeca Buzzo; VELHO, Lea Maria Leme Strini. Entre o campo e o laboratório: a dinâmica de produção de conhecimento no Ambulatório de Menopausa do Caism/Unicamp. História, Ciências, Saúde-Manguinhos, Rio de Janeiro, v.21, n.4, out.-dez. 2014, p.12831300.

\section{Resumo}

Este estudo investiga as práticas de produção de conhecimento sobre a menopausa no Caism/Unicamp, centro de referência para políticas públicas em saúde da mulher. Foram realizadas observações de consultas ginecológicas, entrevistas com mulheres e médicos e observação de reuniões de apoio psicológico, buscando identificar os discursos que circulam no lugar e o processo de alistamento de diferentes atores para que os conhecimentos ali produzidos alcancem credibilidade e "viajem" além dos limites do hospitalescola, tornando-se "universais". A análise baseia-se nos "estudos localistas", alinhados aos estudos sociais de ciência e tecnologia.

Palavras-chave: lugar de produção de verdades; construção do conhecimento; Caism/Unicamp; laboratório científico; menopausa.

\section{Abstract}

This study investigates the practices involved in the production of knowledge about menopause at Caism, Unicamp, a reference center for public policies for women's health. Gynecological appointments and psychological support meetings were observed, and women and doctors were interviewed in order to identify what discourse circulates there and how different actors are brought in to ensure that the knowledge produced attains credibility and "travels" beyond the boundaries of the teaching hospital to become "universal". The analysis is based on localized studies aligned with social studies of science and technology.

Keywords: place for the production of truth; knowledge building; Caism/Unicamp; scientific laboratory; menopause. 
$\mathrm{E}$ m nossa sociedade, a menopausa marca o início de uma nova etapa na vida da mulher, carregada por alterações psicológicas, biológicas e sociais. Os sintomas mais frequentes atribuídos à baixa na produção de estrogênio pelos ovários - são as ondas de calor (fogachos), atrofia vaginal, mudança de humor, depressão, diminuição da libido, osteoporose, insônia, entre outros (OMS, 1996).

Cerca de 72 milhões de mulheres no mundo, entre as quais dois milhões de brasileiras, relatam sintomas da menopausa (Rozenfeld, 2007). Apesar do número expressivo, pesquisas comparativas indicam que, em algumas sociedades, a ocorrência da menopausa é desconhecida, não havendo sequer um termo para designar tal fase (Vigeta, Brêtas, 2006). Assim, a menopausa não pode ser considerada um "fato natural", universal ou padronizado, mas um conceito particular e relativo, cujas fronteiras e significados dependem do ponto de vista de cada interlocutor (Lock, 1993; Trench, Santos, 2005) e dos lugares específicos em que são produzidos (Shapin, 1995).

Este estudo acompanha o Ambulatório de Menopausa do Centro de Atenção Integral da Mulher (Caism) - um renomado hospital-escola brasileiro - como um lugar legítimo de produção de verdades sobre o corpo da mulher na menopausa. A análise concentra-se na cena médica, local de encontro entre dois importantes atores envolvidos na construção desse conhecimento - o médico e a paciente. O médico aqui é um aprendiz dentro do hospital-escola, que busca, ao mesmo tempo, "ver" com os olhos de seu professor, conhecer a natureza, decifrála e traduzir esse discurso recém-descoberto. Essa tradução, quando dentro do consultório, tem a finalidade de alistar as mulheres pacientes para que aceitem o discurso médico como verdadeiro e permitam que o conhecimento finalmente se efetive por meio de seus corpos.

O material etnográfico foi coletado no período de setembro de 2009 a outubro de 2010. Foram realizadas 28 entrevistas detalhadas com mulheres pacientes, envolvendo temas como a primeira menstruação, início da vida sexual, sentimentos em relação à menopausa, medicamentos utilizados, além de informações socioeconômicas da entrevistada, com duração média de 15 minutos. Também foram realizadas 15 entrevistas com médicos, dos quais sete eram residentes e oito eram alunos do sexto ano de graduação em medicina, buscando identificar como definiam a menopausa, seu diagnóstico e tratamentos médicos. Foram ainda observadas 64 consultas ginecológicas do Ambulatório de Menopausa, ${ }^{1}$ com entrevistas complementares às mulheres atendidas. Todos os médicos acompanhados foram entrevistados após seu expediente de consultas. Além disso, foi feito o acompanhamento de dez sessões do grupo de psicologia que prestava atendimento às mulheres na menopausa (envolvendo dez mulheres), parte importante do serviço oferecido pelo ambulatório. As entrevistas, consultas médicas e reuniões de psicologia foram gravadas e parcialmente transcritas. Por questões éticas, apenas uma das pesquisadoras ${ }^{2}$ teve acesso à sala de consultas, ficando também responsável pelo acompanhamento das reuniões do grupo de psicologia. No total, a pesquisa envolveu 99 mulheres pacientes e 15 médicos-aprendizes, somando cerca de cinquenta horas de gravação.

A análise pauta-se nos "estudos localistas", alinhados aos estudos sociais de ciência e tecnologia, que investigam a produção de conhecimento nos lugares onde são construídos, conforme se apresenta, sucintamente, na próxima seção. Segue-se, então, uma discussão sobre os fatores que tornam o Caism um lugar legítimo de produção de verdades sobre o corpo da 
mulher, direcionando políticas públicas nessa área. As seções subsequentes analisam o processo de construção de um conceito compartilhado de menopausa entre os atores observados.

\section{O papel do lugar na construção de fatos científicos}

Diversos estudos têm atribuído categorias a diferentes práticas do conhecimento científico baseadas no lugar em que elas acontecem, analisando também o comportamento dos pesquisadores com respeito às particularidades de cada lugar (Henke, 2000). Consideram que o lugar não é meramente um cenário, mas um jogador atuante nas relações sociais. Os fatos sociais estão vinculados a um lugar específico e incorporam características desse lugar (emplaced), do mesmo modo que os lugares construídos pelo homem incorporam significados simbólicos que podem ser compreendidos visualmente e impõem códigos da prática cultural (Gieryn, 2000). Dessa forma, o estudo do lugar é uma importante ferramenta para compreender determinada cultura (Kohler, 2002).

A abordagem localista contribuiu para a abertura de novas possibilidades de análise aos estudiosos da ciência, uma vez que transcende o "contexto da descoberta" e analisa as estruturas de "justificação" e a "viagem" do conhecimento de lugar para lugar (Shapin, 1995). Conforme destacam Latour e Woolgar (1997), compreender o processo de construção de conhecimento exige que se acompanhe tal "viagem" por intermédio das malhas da rede em que se faz e desfaz determinado fato científico.

O campo e o laboratório são lugares privilegiados de produção de verdades. Como truthspots - locais que permitem o acesso à "verdade" - ambos conferem credibilidade às afirmações científicas neles produzidas, contribuindo para a aceitação social das mesmas (Shapin, 1995; Gieryn, 2006). Apesar desse traço comum, a cada local se associam características diferentes: o campo proporciona acesso à verdade por meio de observação, experiências subjetivas, imersão, aproximação local, diferentemente do laboratório, cujas práticas se baseiam em experimentação, objetivação, distanciamento, generalizações (Gieryn, 2006).

A credibilidade das afirmações científicas desenvolvidas no laboratório depende grandemente do "desaparecimento" do lugar e das circunstâncias de sua produção. O conhecimento tem que passar a ser verdade em todos os lugares, adquirir uma "universalidade espacial" (Gieryn, 2002). As afirmações científicas têm pouca credibilidade se forem verdadeiras apenas em um lugar particular.

A rede por onde um determinado conhecimento viaja se encarrega de fortalecer e proteger esse conhecimento. Shapin (1995) exemplifica que o conhecimento incorporado em um termômetro seria difícil de ser contestado, uma vez que seria necessário lutar contra várias atividades institucionalizadas que dependem diretamente da manutenção do termômetro como uma "caixa preta". Assim, quando os elementos de uma rede agem em conjunto para proteger um conhecimento, esse conhecimento é então suficientemente forte e reconhecido como científico. Entretanto, durante a viagem o conhecimento nunca chega intacto a outro lugar, dado que não se consegue transferi-lo apenas por meio de algoritmos, receitas, métodos ou regras detalhadas sobre o processo: o trabalho empírico é desenvolvido mediante características locais, equipe qualificada a lidar com os processos, instrumentos tecnológicos e transações entre as pessoas e o conhecimento (Shapin, 1995). É a mobilidade 
espacial do laboratório (o fato de laboratórios "idênticos" poderem ser construídos nos locais mais diversos) que permite que as práticas realizadas no interior dos mesmos se dispersem rapidamente como "espécies invasoras", que viajam e são assimiladas em qualquer lugar, transformando o modo como as pessoas pensam (Kohler, 2002).

A padronização dos laboratórios científicos contribui para a "rotinização" das tarefas e para o "desaparecimento" do lugar como relevante na produção do conhecimento (Gieryn, 2002). Garante também a reprodutibilidade dos experimentos, independente do contexto social, conferindo credibilidade ao conhecimento produzido em laboratórios (Kohler, 2002). Tais lugares, que se organizam de maneiras visualmente semelhantes e partilham regras e procedimentos, dão a sensação de produzir "verdades universais".

Os estudos da ciência atualmente privilegiam o laboratório, o mais "sem lugar" dos lugares, como ambiente para observar a produção de conhecimento (Kohler, 2002). Mas não foi sempre assim. Até o final do século XVIII, os cientistas de campo eram vistos como heróis exploradores, desbravadores, que passavam privação em nome da ciência, e isso garantia sua credibilidade científica. O que mudou essa lógica do lugar de produção de conhecimento foi a emergência do laboratório moderno, que não se utiliza de lugares emprestados à natureza para produzir conhecimento, mas cria lugares próprios para seus habitantes, além de exibir uma lógica de credibilidade distinta que não depende de um lugar específico (Kohler, 2002).

Laboratório e campo não necessariamente se opõem, mas são complementares para a pesquisa científica. O conhecimento pode ganhar legitimidade por preservar as características de ambos os lugares de produção (Gieryn, 2006). Há um tráfego de informações constante através dessa fronteira, e as práticas dos cientistas tendem a combinar métodos de ambos os truth-spots, já que são parte de uma cultura comum e seus princípios de construção do conhecimento são similares (Kohler, 2002). Além disso, alguns trabalhos recentes procuram demonstrar que, em certos tipos de ciência, não é possível visualizar uma divisão tão nítida entre o campo e o laboratório (Henke, 2000).

Os conceitos acima informaram a reconstrução que se fará na próxima seção sobre a criação e consolidação do Caism como um lugar de produção de verdades locais que "viajam" para além dos limites do hospital-escola, conquistando "universalidade" e ampla credibilidade social.

\section{Caism como lugar de produção de verdades}

O Caism é o primeiro hospital da mulher da América Latina, sendo considerado referência no continente pela Organização Mundial de Saúde (OMS). Presta atendimento gratuito às mulheres do município de Campinas e de outras cidades brasileiras, realizando mais de sete mil consultas ambulatoriais ao mês e envolvendo mais de mil profissionais em diversas áreas (Brasil, 2009). Desde sua criação, o Caism já prestou assistência a mais de 1,5 milhão de pacientes, ocupando um conjunto de oito prédios dentro da Universidade Estadual de Campinas (Unicamp) com mais de 15.000m² de área construída (Brasil, 2009).

A localização do Caism dentro da Unicamp reforça o caráter do hospital como lugar de formação, acúmulo e transmissão de saber médico em diversas especialidades. O atendimento clínico serve de treinamento para futuros médicos e é organizado por ambulatórios específicos 
que contemplam o atendimento em diversas fases da vida da mulher. Todos os ambulatórios contam com equipe multidisciplinar para atendimento às pacientes, incluindo especialidades como psicologia, nutrição, assistência social e fisioterapia. Na fase da menopausa, as pacientes do Caism são atendidas em um ambulatório específico, que funciona duas vezes por semana (terças e quartas-feiras) no período da manhã, recebendo em média oitenta mulheres por semana.

Para serem atendidas no Ambulatório de Menopausa, as mulheres devem entregar uma carta de encaminhamento de seu médico de consultório público ou particular e passar por uma triagem realizada no mês de março de cada ano. O atendimento é prestado por alunos do sexto ano de graduação em medicina da Unicamp e residentes de ginecologia. Geralmente, três alunos de graduação - chamados de internos - e um residente de ginecologia são responsáveis pelo atendimento no Ambulatório de Menopausa, sendo os internos substituídos a cada semana, e os residentes, uma vez ao mês. Embora internos e residentes fiquem a sós com a paciente durante a consulta, eles contam com a orientação de seus professores antes de fazer qualquer prescrição.

A importância do Caism para a produção de conhecimento em saúde da mulher (como truth-spot) pode ser entendida pela história de concepção desse lugar. Desde o início, o Caism tem ligação direta com ações governamentais, tornando-se um ponto de passagem para políticas públicas na área de saúde da mulher. Nessa relação estreita com o Estado, o hospital-escola se colocou, desde o início, em uma posição de articulação, e esse fato favorece o desenvolvimento e aceitação social do conhecimento ali gerado. Assim como o laboratório de Beauregard e suas pesquisas com células combustíveis, analisado no trabalho de Callon (1999), o Caism também orienta suas pesquisas a um programa nacional (Programa de Atenção Integral à Saúde da Mulher - Paism) e, como consequência, realiza também um papel de intermediário entre a dinâmica da pesquisa e da ação política. Ao papel de intermediário, Callon (1999) sugere que caberia o gerenciamento (e direcionamento) dos problemas e objetos de pesquisa, visto que "a construção de fatos científicos dentro dos laboratórios é indissociável da estratégia do laboratório no seio das redes que ele gere" (p.177). ${ }^{3}$ Foi na criação do Paism que se concretizou a primeira equivalência entre esse centro de pesquisa e um objetivo político. Essa equivalência entre objetivos heterogêneos postulada por um ator particular é chamada de tradução (Callon, 1999; Latour, 1983, 2000).

O conceito de tradução utilizado por Latour $(1983,2003)$ faz referência à interpretação dada pelos construtores de fatos, orientada para seus interesses e/ou para o interesse de atores que eles alistam. A operação de tradução realizada pelo cientista procura, ao mesmo tempo, alistar pessoas para acreditar e disseminar sua visão, além de se manter no controle para que o conteúdo disseminado por essas pessoas permaneça mais ou menos inalterado (Freire, 2006). Entretanto, as traduções criam equivalências entre discursos, atividades e categorias totalmente distintas e, portanto, geram controvérsias. O cientista então se associa a interesses diversos para que sua tradução da realidade seja aceita pelos demais atores e não seja contestada pela política científica vigente, responsável por destinar os financiamentos para sua concretização (Callon, 1999).

A filosofia de Atendimento Integral à Saúde da Mulher (Aism) ${ }^{4}$ concebida dentro do grupo que veio a se tornar o Caism foi traduzida de modo a alinhar-se às demandas do Estado 
em uma época em que era necessário estabelecer uma política voltada para o crescimento populacional, considerado desenfreado. Uma Comissão Parlamentar de Inquérito (CPI) estava sendo articulada para resolver a questão do crescimento populacional no Brasil, e o Paism foi apresentado nessa ocasião por dois membros do Departamento de Tocoginecologia da Unicamp, enfatizando a questão do planejamento familiar como carro-chefe da proposta (Osis, 1994; 1998). O conceito de Aism já vinha sendo trabalhado pelo grupo da Unicamp, sob a liderança de José Aristodemo Pinotti, desde o início dos anos 1970, mas suas ideias só passaram a figurar no cenário político no início dos anos 1980 - fase na qual Pinotti tornouse também reitor da universidade. Devido às suas fortes alianças políticas, Pinotti conseguiu indicar dois pesquisadores de seu departamento para compor a CPI e propagar suas por intermédio do Paism.

Em 1986, dois anos depois do lançamento do Paism, foi criado o Caism, cujo criador e primeiro diretor executivo foi o então reitor Pinotti. No mesmo ano, Pinotti ingressou oficialmente na carreira política como secretário de Estado da Educação de São Paulo (19861987), na gestão do governador Franco Montoro (1983-1987), tendo assumido em seguida inúmeros cargos políticos. As ideias defendidas por Pinotti por meio do Paism/Caism lhe renderam ainda a presidência da International Federation of Gynecology and Obstetrics (Figo), de 1988 a 1991, implantando em nível internacional o conceito e prática do Reproductive Health, equivalente ao Paism brasileiro. O médico, único brasileiro a presidir a Figo, privilegiou em sua gestão o treinamento de ginecologistas de países em desenvolvimento (Pinotti, 2008; Brasil, 2009; Figo, 2009).

Poucos são os cientistas que veem suas teorias traduzidas em políticas públicas e menos ainda os que têm a possibilidade de participar de sua execução e gerenciamento. Pinotti foi favorecido graças à sua capacidade de "alistar" atores tanto no meio acadêmico quanto político, conquistando as condições necessárias para que suas "traduções" fossem amplamente aceitas. Mediante o Paism, os conhecimentos produzidos localmente passaram a ser generalizados em plano nacional, e o Caism se tornou o lugar modelo para produção de conhecimento em saúde da mulher, em que as práticas médicas são testadas e os protocolos são elaborados para ser aplicados nos demais hospitais da rede pública. Além disso, Pinotti passou a ser referência para falar e legislar em nome da saúde da mulher no Brasil, alcançando prestígio e alianças decisivas em meio à comunidade acadêmica e política, além de importantes recursos financeiros para a consolidação de suas traduções.

Na divulgação do conhecimento científico Pinotti também teve atuação destacada, produzindo ao longo da carreira mais de 1.300 publicações, entre livros científicos, artigos em revistas e jornais nacionais e internacionais (Brasil, 2009). A partir do Paism, diversos programas governamentais foram criados com base no conceito de saúde integral da mulher, como é o caso do Manual da Menopausa. Essas políticas podem ser vistas como resultados concretos das operações de tradução do Caism (e também de Pinotti) em torno das questões de saúde da mulher.

Pinotti faleceu no dia $1^{\circ}$ de julho de 2009, meses antes do início da coleta de dados dessa pesquisa. Em 9 de setembro de 2010 o hospital-escola idealizado por ele ganhou um "sobrenome": Hospital da Mulher José Aristodemo Pinotti - Caism/Unicamp, sob o slogan "Orgulho de ser Caism, orgulho de ser Pinotti" (Sugimoto, 2010; Brasil, 2009). 


\section{Ambulatório de Menopausa: entre o campo e o laboratório}

O Ambulatório de Menopausa do Caism tem um importante papel dentro desse hospitalescola. O espaço destinado às consultas clínicas do ambulatório permite que os pesquisadores e médicos em formação tenham acesso a uma vasta amostra de casos para analisar. Mesmo havendo certos mecanismos de controle naquele ambiente, os médicos estão mais propensos a encontrar imprevistos que possam alterar os rumos de suas pesquisas. Como no campo, eles são obrigados a lidar muito mais com o inesperado, com as "intrusões" de fora, advindas de fatores humanos ou não humanos. Na consulta, o médico-pesquisador tem contato de perto com a paciente e, por meio da observação, tem a possibilidade de avaliar cada caso, considerando suas particularidades.

Por outro lado, o ambulatório é um ambiente controlado, no qual os resultados das pesquisas feitas no local e os casos atendidos no consultório se tornam matéria-prima para a estruturação de conceitos genéricos (muitas vezes em forma de protocolos médicos) a ser utilizados como verdades universais em contextos diversos - no caso, em postos de saúde do Sistema Único de Saúde (SUS). Essas características fazem do Ambulatório de Menopausa um grande "laboratório", no sentido latouriano (Latour, Woolgar, 1997; Latour, 2000; 2001), posto que o atendimento às mulheres torna-se um espaço para atividades de ensino e pesquisa e interação entre atores.

No espaço da consulta clínica, os pesquisadores e médicos-aprendizes buscam cada vez mais instituir rígidos padrões de controle que podem ser percebidos na padronização dos protocolos de atendimento, do corpo e comportamento das pacientes, além do próprio espaço médico. Durante a consulta, o médico faz uso de cada vez mais instrumentos, gráficos, tabelas e exames na tentativa de diminuir a subjetividade ou influência externa observada no "campo" do consultório. Além disso, as impressões pessoais e reações próprias do observador (médico) captadas no campo por meio dos olhos, nariz e ouvidos são substituídas por resultados padronizados de aparelhos, numa tentativa de distanciar o juízo humano durante a análise (Gieryn, 2006). Essa objetivação do ser, considerando-o um objeto a ser tratado de forma impessoal e abstrata, tem por finalidade transformá-lo em algo passível de manipulação e controle (Rice, 2008) e representa uma fase fundamental para a construção do conhecimento científico (Foucault, 1977). Dessa forma, o campo presente no espaço do consultório médico tenta distanciar-se da mera observação local, individual para tornar-se uma extensão do laboratório, mais um espaço de experimentação que busca neutralidade e objetividade de análise.

A aproximação do consultório ao laboratório pode ser observada também em sua padronização espacial: a disposição da mesa, o espaço destinado às pacientes, os cartazes pregados no consultório, os panfletos informativos, os instrumentos médicos, a maca, o jaleco branco, entre outros. Tais elementos visuais/materiais servem como suporte ao discurso produzido localmente, contribuindo para a credibilidade e suposta neutralidade desse conhecimento e favorecendo a disseminação (e universalização) das verdades produzidas. Essa organização espacial fortalece ainda o poder disciplinar do médico dentro do hospital, reflete as hierarquias do lugar e contribui para o controle social.

Muitas outras ações desse ambulatório, como a própria triagem das pacientes, passam por algum tipo de controle: um dos critérios fundamentais para a seleção dos casos é o 
enquadramento das pacientes às necessidades de pesquisa do departamento de tocoginecologia do hospital-escola. Dessa forma, os alunos de pós-graduação podem executar a fase de coleta de dados de campo e testar hipóteses da pesquisa de mestrado ou doutorado dentro da própria universidade, tendo a possibilidade de realizar entrevistas e/ou consultas com mulheres frequentadoras do Ambulatório de Menopausa. Nesse sentido, campo e laboratório se aproximam: o que é observado no campo é geralmente analisado à luz das "leis gerais" codificadas/construídas no laboratório, da mesma forma que as fontes coletadas em campo servem muitas vezes de base ("amostras") para orientar e ratificar pesquisas no laboratório. Percebe-se, assim, a sobreposição dos espaços do campo e laboratório no contexto do Ambulatório de Menopausa e a complementaridade entre eles na construção dos fatos científicos.

\section{Da teoria à prática médica}

Os casos atendidos no consultório médico oferecem subsídios para avaliação dos procedimentos médicos utilizados, além de possibilitar o teste e a revisão de diversos protocolos de atendimento. As hipóteses de trabalhos dos pós-graduandos são também colocadas à prova com base nos casos atendidos, e, durante as consultas, há a possibilidade de captação de novas demandas, inspirando futuras pesquisas científicas. Há, portanto, constantes construção, negociação e reprodução do conhecimento científico sobre o corpo da mulher na menopausa naquele ambiente.

Foucault (1979) atribui à emergência do sistema hospitalar uma série de mudanças na prática médica, incluindo a transformação do indivíduo em objeto de saber e intervenção médica. O hospital passou a deter um vasto campo documental (registro de dados dos pacientes), deixando de ser somente um local de cura, para ser também de acúmulo e formação de saber (Foucault, 1979). Nesse sentido, pode-se observar que o hospital-escola constrói mais do que fatos científicos - constrói, antes de tudo, os próprios construtores de fatos, uma vez que capacita os recursos humanos necessários para reproduzir os "experimentos" desse laboratório. Além disso, os testes, tanto de um protocolo médico quanto de um trabalho acadêmico podem ser vistos como "experimentos" do laboratório, em que o corpo da mulher serve como objeto de pesquisa e intervenção médica.

No consultório médico, o tratamento dado ao corpo das mulheres por meio de um método padronizado (protocolo) parte da premissa de que a menopausa provoca efeitos similares em todas as mulheres, independente do contexto ou das particularidades da vida de cada uma. Apesar de todas as recomendações do Caism e Paism para um atendimento integral, na prática médica inúmeras generalizações podem ser observadas:

Médico: A gente acha que assim, porque um dos hormônios que a mulher produz que é o estrogênio, né? - que produz lá no ovário, vai diminuindo com o avançar da idade, as células reprodutivas da mulher, que são os óvulos, vão acabando e eles que produzem o estrogênio.

Paciente: Sei.

Médico: ... a mulher vai passando pelo período fértil, aí vai acabando essas células e vai produzindo menos estrogênio. $\mathrm{O}$ fato de produzir menos estrogênio é o que a gente 
acha que dá esses sintomas de calor, a secura vaginal, às vezes pode dar um pouquinho de depressão na mulher, dá problema no osso, o osso começa a incorporar menos cálcio. Por isso que a gente entra em alguns casos com sintomas mais avançados.

Paciente: Entendi. Então esse aí é um hormônio, né, doutor?

Médico: É.

Paciente: E vou tomar por tempo indeterminado?

Médico: É. Na verdade é... o ideal é que, assim, não é pra vida inteira, é por essa fase que a senhora tá passando. Certo?

Paciente: Certo. (Andréia, 55 anos.)

Nesse caso ilustrativo, o médico descreve a sucessão de acontecimentos no corpo da mulher com a chegada da menopausa e coloca a baixa produção de estrogênio como explicação para todos os males, desde os mais variados sintomas físicos como "secura vaginal", "osteoporose" e "ondas de calor" até sintomas psíquicos como a "depressão", todos tratados com "hormônios". Na prática médica, a abordagem "integral" de atendimento à mulher era substituída pelo parcelamento e "biologização" do corpo feminino, cujas características são tidas como "universais". Esse tratamento parcelado pode ser observado também em outros momentos, em que os médicos se recusavam a escutar qualquer outra queixa das mulheres que, na visão deles, não tivesse ligação direta com a menopausa: "aqui nós só atendemos casos que são relacionados com a menopausa" ou "isso a gente não vê aqui, a senhora tem que ver lá no posto de saúde, com o clínico geral".

Por outro lado, o protocolo seguido pelos futuros médicos durante as consultas inclui questões socioculturais sobre a vida das mulheres. As questões abrangem a alimentação da paciente, exercícios físicos, relação de medicamentos utilizados, relação sexual, sangramentos ou corrimentos vaginais, além dos sintomas físicos e psíquicos entendidos como próprios da menopausa. Embora o protocolo abarque tais questões de cunho psicossocial, os sintomas mesmo os psicológicos ou decorrentes de problemas sociais/familiares - são interpretados como tendo origem estritamente biológica, oriundos de uma baixa produção hormonal e sem qualquer relação com outros aspectos da vida da paciente, sendo, consequentemente, tratados via medicamentos. Esse é um aspecto fundamental do processo de medicalização em seu nível interacional (Conrad, 1992), segundo o qual o médico passa a identificar um problema qualquer como sendo da alçada médica ou ainda oferece tratamento médico para um problema social.

Na consulta conduzida pelos médicos-aprendizes, o roteiro de questões do protocolo e o prontuário pareciam ser mais importantes para o médico do que a própria paciente ali presente que, muitas vezes, não recebia sequer um olhar. Em diversas consultas gravadas, o silêncio do médico aprendiz ao ler o prontuário durava mais de 15 minutos, deixando a paciente apreensiva. O "ritual" da consulta parecia opressor para a paciente - diante do médico ela só respondia ao que era perguntado e, por vezes, esquecia, não tinha tempo ou até mesmo abertura para questionar sobre o que estava sentindo: "a gente tem só cinco minutos para lembrar de tudo e às vezes eles nem olham na nossa cara!", justificava a mulher. Frequentemente, quando o médico aprendiz saía da sala para consultar o professor e me deixava a sós com as mulheres (o que demorava cerca de vinte minutos), elas pediam para que 
eu as ajudasse a lembrar o que gostariam de perguntar ao médico, já que não conseguiam se lembrar de suas dúvidas quando o médico estava presente: "me lembra de falar que eu tô com dor na perna, não esquece!" ou "esqueci de falar pra ele que estou com dor no rim. Quando o médico voltar, você me lembra de falar isso pra ele?". Em geral, as mulheres se mostravam tensas no encontro com o médico, o que as levava ao esquecimento de suas dúvidas ou ao desconforto para questionar.

Outras vezes, quando as mulheres tinham oportunidade (e coragem) de falar espontaneamente sobre o que estavam sentindo, percebiam que o médico não lhes dava atenção. $\mathrm{Na}$ sala de consulta, eu ficava em uma cadeira no canto direito, pouco atrás das pacientes e, mesmo fora do seu campo de visão, elas se viravam para me olhar e costumavam me incluir no diálogo da consulta. Apesar de ter sido esclarecido previamente que eu não era médica, quando não recebiam a devida atenção do médico elas insistiam em me mostrar suas pernas inchadas e doloridas, mãos e braços castigados pela artrite, ou me faziam apertar também algum "caroço" na cabeça, no braço, nas costas para que eu testemunhasse seu sofrimento e pudesse ser solidária à sua dor.

O distanciamento entre o futuro médico e a paciente se estendia ao exame clínico. Os futuros médicos realizavam exames clínicos somente quando a mulher se queixava de alguma dor ou irregularidade. Os residentes raramente faziam esses exames no consultório, já que acabavam sendo responsáveis por atender um volume maior de mulheres por ter mais prática de trabalho. Enquanto os internos dedicavam entre quarenta minutos e uma hora por consulta, os residentes gastavam - no máximo - dez minutos em cada caso. Como todos os casos tinham que ser atendidos ainda no período da manhã, e os internos não conseguiam dar conta de um número tão alto de pacientes, o residente em atendimento deveria apressar seu tempo de consulta. Por conta disso, geralmente selecionava casos mais simples, de rotina, em que a mulher estivesse na menopausa há muito tempo e necessitasse apenas de pedidos novos de exames laboratoriais e acompanhamento de osteoporose. Esse fato era um motivo de frustração para muitos residentes:

[Fala da médica quando peço para acompanhar suas consultas]

Sou residente. Aqui é vapt-vupt, não assusta! Se você for acompanhar os estudantes, demora mais, mas aqui é muito rápido, não dá para atender direito. (Médica residente, 28 anos)

[Médica fala para enfermeira]

Eu falei para a [professora]: "Isso não é ambulatório de menopausa, é ambulatório de osteoporose". Tenho dó das avós, mas eu não vou tratar caso de osteoporose grave aqui. Prática, conhecimento como residente de ginecologia mesmo a gente não tem aqui. (Médica residente, 28 anos.)

Os residentes tinham mais conhecimentos "práticos" da profissão, prestavam um atendimento rápido, além de ter maior autonomia de trabalho. Contudo, a diferença de atendimento entre alunos e residentes não se restringia a esses fatores. A atenção dada pelo interno à paciente era muito maior: na maioria das vezes, fazia um exame clínico detalhado, não só estimulado pela prevenção da saúde da mulher atendida, mas alegando ser uma oportunidade de "aprender na prática", uma oportunidade a mais para "aprender a ver". 
A postura de muitos aprendizes, deixando a paciente em segundo plano, pode ter sido estimulada pela forte cobrança sobre o tempo de atendimento, já que o aprendiz tem que dar conta de uma detalhada rotina de atividades durante a consulta. A rotina do aprendiz inclui ler atentamente todo o prontuário da paciente, seguir as questões do protocolo, ouvir as queixas da paciente, realizar exames clínicos (quando necessário), verificar os exames laboratoriais e, a seguir, transcrever o que foi observado. O prontuário médico funciona como um "diário de campo", em que há registros de experiências pessoais e percepção do observador em cada momento (Gieryn, 2006; Foucault, 1979). Após a atualização do prontuário, o aluno deve levar suas inscrições ${ }^{5}$ (baseadas tanto em resultados de exames laboratoriais quanto na sua avaliação clínica) como referência para consultar o professor sobre qual o melhor procedimento a ser seguido. O aluno deve, assim, "aprender a ver a natureza" sob a perspectiva da ciência médica, já que essa natureza não é autoevidente dentro do consultório.

Na prática de ensino médico, a prescrição do tratamento e identificação de patologias passava, então, pela "inscrição" do futuro médico do que foi observado na consulta, pela "leitura" e "tradução" da inscrição do aluno pelo professor e, posteriormente, pela interpretação do aluno sobre as orientações do professor, mas, antes de tudo, passava pelas negociações de significados atribuídos por médico e paciente - antes e depois do "fechamento" da consulta. Entretanto, há uma assimetria de poder evidenciada no momento de negociação de significados, tanto na relação do futuro médico com a paciente quanto do futuro médico com seu professor. A vivência da mulher sobre seu próprio corpo é, muitas vezes, sobreposta pelo conhecimento do futuro médico, assim como a visão do futuro médico - que teve contato direto com a paciente - é sobreposta pela visão do médico professor. Assim, o fechamento da consulta com consequente diagnóstico e prescrição médica se dá no nível mais distante possível da paciente.

É importante destacar que a generalização promovida pelo protocolo não dá conta da complexidade e variabilidade de casos apresentados no consultório médico (Stricker, Trierweiler, 1995). Assim, há diversas situações no consultório que fogem claramente do escopo da generalização, e a estratégia clínica tem, então, que ser modificada. Dessa forma, não há aplicação imediata do conhecimento científico produzido em laboratório para o consultório médico. O médico clínico tem que fazer ajustes, tradução, adaptação, revisão e a reconstrução do conhecimento produzido no laboratório (Stricker, Trierweiler, 1995). No caso estudado, o conhecimento produzido sobre o corpo da mulher no Ambulatório de Menopausa não reside apenas no consultório médico como um campo de pesquisa ou como um laboratório, pois durante a própria prática de ensino há um processo de construção e reconstrução desse conhecimento por parte dos aprendizes e professores.

Nesse contexto, para que o aprendiz "aprenda a ver", ou seja, relacione a teoria médica aprendida ao caso "prático" visto no consultório, são necessários alguns ajustes. Sobre essa relação teoria/prática, Deleuze (Foucault, Deleuze, 1979) afirma que uma teoria é sempre local e atrelada a um pequeno domínio, mas pode ser aplicada em um domínio diferente. Entretanto, a aplicação dessa teoria nunca parte de uma relação de semelhança - mesmo que a teoria seja aplicada em seu próprio domínio, encontra obstáculos, sendo necessário um "revezamento" por outro tipo de discurso. São esses "revezamentos" de discurso que permitem que uma teoria seja aplicada tanto em seu próprio domínio como em outros, diferentes. 
Concluindo, "a prática é um conjunto de revezamentos de uma teoria a outra, e a teoria, um revezamento de uma prática a outra" (Foucault, Deleuze, 1979, p.40). Portanto, "aprender a ver" ou aprender a fazer tais "revezamentos" da teoria médica aprendida é o passo principal para o aprendiz tornar-se apto a exercer sua profissão.

Como um aprendiz, o médico observado não tem habilidade nem permissão para fazer tais "revezamentos" sem auxílio, devendo apenas reproduzir a visão do médico professor, ou melhor, ver com olhos do expert. Essa postura ficava ainda mais evidente durante as entrevistas, quando era questionada a opinião desses futuros médicos sobre determinado assunto: "sabe, eu nunca pensei sobre isso antes" ou "até agora a gente não pode pensar sobre nada, a gente só segue o que os professores acham". Nesse sentido, o ensino médico serve como forma de manter e disseminar a verdade produzida no hospital-escola, onde os aprendizes são alistados para esse fim.

Para o aprendiz, o processo de aprendizado através dos "olhos do professor" implica aceitar inteiramente sua posição, interesses e visões que, muitas vezes, passam pela relação desse profissional com a indústria farmacêutica. Como um interno, ele não pode receber a visita dos representantes da indústria farmacêutica, ao contrário dos residentes, sob a alegação de que não estão suficientemente preparados para lidar com a abordagem da indústria e de que não conseguem distinguir o que é "realmente" bom para os pacientes. Assim, o professor é o responsável por fazer essa mediação, apresentando sua interpretação pronta para o aluno:

A indústria farmacêutica exerce sim sua influência sobre a classe prescritora, a classe de médicos. Acho que esse impacto existe tanto dentro da universidade pública quanto lá fora, só que o impacto é muito menor aqui, tá? E muitas vezes a gente não tem como separar, entendeu? ... Eu preciso deles e eles precisam de mim. ... existem vários tipos de influência, elas são tanto benéficas quanto maléficas. A benéfica é aquela relacionada com a pesquisa, a pesquisa pura, aplicada, sobre a expansão do conhecimento médico para o tratamento das pessoas, então é uma influência... não dá só para o Estado dar conta de toda a pesquisa em saúde no país. ... Na pesquisa também aparecem esses dois vieses. Existem muitas pesquisas que são encomendadas, e quando ela é encomendada, o que o indivíduo faz? Às vezes ele pode ocultar dados estatísticos, isso aparece. Aparece maquiado nas estatísticas, se você tiver sorte e tiver experiência você consegue perceber, se você não tiver, você não percebe e acaba sendo influenciado a prescrever uma medicação sobre a outra ... E, por outro lado, existe o formador de opinião, que é o meu professor, ele sofre uma influência direta dos laboratórios, ele depende diretamente deles e eles dependem da gente. A influência da indústria farmacêutica não vem diretamente a nós, mas vem diretamente através dele. ... Uma coisa que é inegável é a influência que o professor, o docente, exerce sobre os seus alunos. $\mathrm{O}$ aluno, conforme ele amadurece seu raciocínio, seu conhecimento médico, ele se torna independente disso, ele passa a tirar suas próprias conclusões (Aluno de medicina, 22 anos).

Do outro lado, as pacientes colocam sua saúde sob o controle de seus médicos, já que em grande parte dos casos elas acreditam em uma "neutralidade" da prescrição médica. A medicina é considerada uma forma de expertise, e, dessa forma, a consulta médica pode ser vista como um encontro com um expert (Collins, Pinch, 2005). A autoridade do médico é socialmente legitimada por seu conhecimento científico, o que o torna apto para diagnosticar e tratar os "males" da paciente. Dessa forma, no contexto do Ambulatório de Menopausa, as orientações dadas 
pelos futuros médicos (mesmo sendo aprendizes) raramente são contestadas pelas pacientes, ao passo que o conhecimento e as vivências relatadas pelas pacientes são constantemente questionados pelos futuros médicos. Nesse caso, percebe-se uma forma hierárquica do saber: o saber científico é tido como verdadeiro, e o conhecimento popular é considerado crendice ou mito, sendo socialmente desvalorizado. No entanto, a ciência não costuma ser reflexiva sobre a produção cultural de seu próprio conhecimento, não reconhecendo o quanto também é rodeada por mitos, principalmente quando se trata do corpo da mulher.

\section{O alistamento das pacientes}

Desde a criação do Caism, do conceito de atendimento integral à mulher, do alistamento de agentes políticos e intelectuais por Pinotti, até as novas pesquisas realizadas no hospital, a criação de protocolos a ser absorvidos por programas públicos, as relações com a indústria farmacêutica e a divulgação científica por meio das palestras e da mídia, o conhecimento produzido nesse truth-spot "viaja", passando e sendo modificado pelos inúmeros nós dessa rede, na qual o corpo da mulher é mais um nó.

A tradução elaborada pelos médicos durante a consulta serve para que as mulheres pacientes sejam socializadas sobre os conceitos construídos pelos médicos a partir de seu corpo. Mais do que socializá-las, essa tradução serve para alistá-las, já que seu corpo é um agente importante na rede de construção do conhecimento. O corpo da mulher faz parte, ao mesmo tempo, da "descoberta" dos conceitos - já que a partir dele se criam esses conceitos - e de sua "justificação" - o conceito só é "efetivado" por intermédio do corpo, no corpo.

Nesse contexto, o corpo da mulher pode ser compreendido como um lugar que, assim como os outros lugares de produção de verdade, está destinado a desaparecer do contexto de produção do conhecimento. Os aspectos socioculturais da vida da paciente são desconsiderados durante a consulta médica, dando espaço apenas aos fenômenos do corpo biológico, o qual é entendido como universal - um lugar-padrão que não pode ser questionado, tampouco localizado. Dessa forma, o que é verdade para um corpo específico passa a ser verdade para qualquer corpo.

A entrada nesse corpo-lugar também depende de traduções. Em geral, essas traduções ocorrem dentro do consultório médico: a permissão que determinada teoria se efetive no corpo se dá mediante tradução do médico para a paciente, que permite ou restringe esse acesso. As mulheres são alistadas para disponibilizar seus corpos, e isso garante a pesquisa e a difusão da verdade produzida. Tudo isso evidencia que o corpo não é um simples receptáculo do conhecimento produzido externamente, mas um lugar de produção e transformação desse conhecimento.

Dado o grande número de pesquisas desenvolvidas no lugar, as pacientes estavam acostumadas a participar de pesquisas e estavam sempre dispostas a dar entrevista ou ser acompanhadas durante as consultas médicas. Diversas vezes me relatavam estar participando de mais de uma pesquisa ao mesmo tempo e se mostravam satisfeitas com isso. Algumas vezes, as mulheres pediam para ser voluntárias da minha pesquisa quando me viam abordando pacientes para entrevistas. Frequentemente diziam que eu não precisaria explicar todo o Termo de Consentimento Livre e Esclarecido (TCLE), porque estavam cientes de que os dados 
seriam usados somente para fins de pesquisa - o que viam como uma oportunidade para dar alguma contribuição ao desenvolvimento científico ou retribuir atendimento recebido. A manifestação das mulheres em favor do Caism justifica o fato de estarem sempre disponíveis para ser voluntárias de pesquisas, fazendo-se úteis, como uma retribuição aos cuidados prestados pelo hospital-escola - o que era encarado como uma relação de troca.

Paciente pergunta para médica: Você conheceu o Dr. [nome], cardiologista?

Médica residente: Não, não lembro não.

Paciente: Então ele já aposentou. Ele era meu médico, era professor aqui. Eu fiquei com ele quase 25 anos. Ele tinha pesquisa e a gente tudo fazia com ele... pesquisa com remédio que vinha dos EUA. Fazia pesquisa pra ver se dava certo ou se não dava. Só uma vez que não deu certo, coitado, ele ficou tão triste. Nós estávamos em vinte pessoas, e ninguém se deu com o remédio, ao invés da pressão abaixar, a pressão subia mais.

Médica residente: Era do estudo?

Paciente: Era, um estudo.

Médica residente: A senhora tá acostumada então?

Paciente: Já... ihh... nossa!!!

Médica residente: Tem que fazer estudo, né? Pra ir melhorando as coisas...

Paciente: Mas é, né? Mas eu falava assim pra ele: 'é doutor, tá fazendo nós de cobaia, né?'. Ele achava graça. É que se vem pra cá [o remédio] e não dá certo, lá nos EUA eles já descartam, não fornece mais. Só sei que nós era uma turmona, ninguém se deu... e a gente vinha toda terça-feira. (Rita, 62 anos, negra, primeiro grau incompleto.)

Nesse caso, a paciente tinha plena consciência de seu papel de "cobaia" na pesquisa, foi informada pelo TCLE, entretanto, aceitava essa condição, muitas vezes por acreditar que a pesquisa era um meio de "ir melhorando as coisas", e essa era uma obrigação de sua parte, já que recebia tratamento gratuito. Foucault (1977) argumenta que o papel dos hospitais é atender a população pobre ao mesmo tempo em que proporciona treinamento aos seus estudantes de medicina. Há uma espécie de contrato implícito, no qual o paciente se sente obrigado a ceder seu corpo para treinamento médico em troca de um tratamento gratuito (Rice, 2008).

Também era muito frequente, depois de uma entrevista ou observação de consulta, as pacientes perguntarem se as informações que elas passaram tenham sido úteis e até se desculparem se não tivessem sabido responder a alguma pergunta. Como minhas perguntas não eram de caráter médico, foi muito questionado por elas de que maneira suas experiências de vida poderiam servir para alguma pesquisa, visto que estavam acostumadas a participar de pesquisas disponibilizando apenas seus corpos e não seus conhecimentos ou experiências sobre os corpos - em grande parte das pesquisas médicas, seus corpos "falavam" por si e cabia apenas ao médico decifrá-los.

Só algum tempo depois percebi que o discurso daquelas mulheres sobre a prática científica era, em grande parte, um reflexo do discurso dos pesquisadores sobre o tema - como agentes alistadas para reproduzir os fatos criados naquele campo-laboratório. Algumas vezes presenciei pesquisadores interrompendo consultas para abordar pacientes que estavam no perfil de amostra para sua pesquisa, e o discurso de contribuição para o avanço da ciência era muito frequente. 
Médico pesquisador: Eu vim conversar com a senhora o seguinte: eu tava conversando com o médico sobre o caso da senhora. A senhora tá entrando na menopausa, né? Tá tendo calorão...

Paciente: É... eu não sei se felizmente ou infelizmente (risos).

Médico pesquisador: É o seguinte. Eu sou o médico responsável e tô fazendo um protocolo de pesquisa sobre mulheres que fizeram transplante de fígado aqui do hospital. Então a gente está estudando a menopausa em mulheres que fizeram transplante de fígado, tá. Só que, pra comparar, a gente vai precisar comparar, vamos precisar estudar a menopausa também naquelas que não fizeram transplante, que estão sem doença, que é o caso da senhora. E eu ia convidar a senhora pra ver se a senhora não quer entrar nesse protocolo de pesquisa. E qual é o benefício pra senhora? Porque assim, hoje eu ia pedir pra senhora voltar na semana que vem, porque estou sem a pasta, eu ia pedir ultrassom, exames ginecológicos, densitometria óssea, ia pedir exames laboratoriais.

Paciente: Isso é necessário pra mim?

Médico pesquisador: Isso. São necessários pra senhora, a gente já ia pedir, tá. O ruim é que até você conseguir fazer esses exames ia demorar muito, tá, principalmente o exame de densitometria óssea, pra ver se tem osteoporose ou não. ... Só que pra fazer a densitometria óssea demora meses, às vezes seis meses pra conseguir fazer a densitometria. O bom desse estudo é que a gente tá conseguindo fazer a densitometria no dia. A senhora entendeu? Eu queria convidar, se a senhora quiser... se a senhora não quiser, claro, se não quiser, a gente pede hoje pra dar sequência normal. ... E a gente tem ajuda de custo pra senhora vir na semana que vem. ... Eu tô convidando porque com certeza é bom, a senhora ia ter que voltar vários dias para fazer esses exames, e dias diferentes. ...

Paciente: Mas isso interfere o que na minha vida? Eu ia ser encaixada nesse programa?

Médico pesquisador: Isso, a senhora viria semana que vem e depois ia continuar o acompanhamento normal, como se fosse hoje, a senhora entendeu? ... Ia acelerar os exames da senhora, só.

Paciente: E ajudar vocês também a fazer a pesquisa, porque eu não vou fazer os exames num dia só pra nada...

Médico: Não... Ajuda a gente, também... Ajuda todo mundo, na verdade, porque a pesquisa é para o avanço da humanidade. ... A senhora não vai ser cobaia de nada não... não é estudo que vai dar remédio diferente não.. Na verdade, pra senhora, vai ser bom. Pra mim vai ser bom também, porque eu vou ter mais uma paciente para comparar ...

Paciente: Eu não tenho faculdade não, mas eu tenho muita sabedoria. Pra ser cobaia eu não aceito. Mas se é pra isso que o senhor tá falando, se é pra ajudar a humanidade, tudo bem então, pra isso que eu tô nessa terra, para o meu lado espiritual. Pra mexer no meu organismo, pra ser cobaia eu não aceito não. (Ana, 55 anos, branca, primeiro grau completo.)

Antes de analisar o modo como ocorria o alistamento das pacientes, deve-se observar a própria pesquisa que envolvia a criação de um "protocolo de pesquisa" com mulheres transplantadas de fígado na menopausa e outras que não fizeram transplante e estavam na menopausa. Pode-se perceber uma tentativa de expandir ainda mais a categoria menopausa e seus sintomas associados. A partir da definição biomédica da menopausa como doença, o Ambulatório de Menopausa do Caism assimilou tal definição e passou a utilizá-la como base 
para sua produção de conhecimento sobre o corpo da mulher, que inclui a ampliação dos efeitos/sintomas da menopausa.

O alistamento das pacientes como voluntárias da pesquisa possibilita que elas "testem" em seu próprio corpo as verdades produzidas no Ambulatório, fase crucial para a produção, justificação e expansão do conhecimento. Assim, no momento da abordagem, as vantagens expostas pelos pesquisadores refletem sempre uma visão de ciência neutra, livre de interesses, "para o bem da humanidade", em contraponto com as desvantagens que praticamente não aparecem nesse momento de abordagem. Com os argumentos colocados, é difícil para a paciente se opor - ela se sentia constrangida em negar; afinal, quem quer ser responsável por prejudicar o "bem da ciência" ou "avanço da humanidade"?

Entretanto, deve-se perceber também que o alistamento dentro do consultório concede espaço de negociação entre médico e paciente. Se, por um lado, os médicos pesquisadores tentam convencer a paciente a participar da pesquisa, por outro, as mulheres se interessam pelas compensações trazidas por essa participação. Muitas vezes a mulher se coloca no papel de "coitada", enfatizando que só aceita participar da pesquisa para ajudar, entretanto, sabe que se trata de uma "barganha" em que, cada vez mais, sua representação de "submissa" e "coitada" pode aumentar as vantagens decorrentes de sua participação na pesquisa. Além disso, ser voluntária das pesquisas desenvolvidas no lugar é, para muitas mulheres, uma garantia de continuarem sendo atendidas naquele hospital-escola. Nesse "jogo" de relações na construção do conhecimento, as mulheres são ao mesmo tempo objetos operados pelo saber médico e sujeitos, visto que o fato de elas terem aprendido a "cumprir" um papel "submisso" naquele ambiente pode ser entendido como uma estratégia própria das mulheres para continuar ativas no jogo.

\section{Considerações finais}

Mediante sucesso dos alistamentos feitos inicialmente por Pinotti para que o Caism fosse criado e sua filosofia chegasse a ter um papel determinante nas políticas públicas sobre o corpo da mulher, pode-se perceber que esse hospital-escola consolidou-se como um centro de referência de práticas inovadoras voltadas para a saúde da mulher ou, ainda, um lugar legítimo de produção de verdades sobre o corpo da mulher.

No decorrer do artigo, acompanhou-se o Ambulatório de Menopausa do Caism simultaneamente como um campo de pesquisa e um laboratório de produção e reprodução de conhecimentos sobre o corpo da mulher na menopausa. As características de ambos os espaços de produção de verdade se sobrepunham dentro do ambulatório, especialmente no consultório médico, oferecendo subsídios para as pesquisas realizadas no hospital-escola.

No entanto, as verdades produzidas localmente precisam "viajar" por entre as malhas da rede para se tornar universais e alcançar credibilidade social. Para tanto, o lugar de produção de conhecimento deveria desaparecer. O desaparecimento do lugar deve-se em grande parte à sua padronização, para que esse lugar não seja colocado em questão e a verdade ali produzida passe a ser verdade em qualquer lugar. Assim, a padronização de lugar, espaços, protocolos e corpos garantia que a verdade produzida naquele ambiente particular pudesse ser verdade em qualquer lugar e em qualquer corpo. Nesse ponto, o corpo da mulher é visto como um 
lugar que também estava destinado a desaparecer do contexto de produção do conhecimento científico. Essa questão ficava mais evidente quando os aspectos socioculturais específicos da vida das pacientes eram desconsiderados durante a consulta médica, dando lugar apenas aos fenômenos do corpo biológico, entendido como universal, que não poderia ser questionado ou localizado. Como consequência, o que era entendido como verdade para um corpo específico, passava a ser generalizado para qualquer corpo.

Em geral, as mulheres pacientes se sentiam em "dívida" com os médicos do Caism pelo fato de serem atendidas em um hospital de qualidade e, especialmente, "gratuito". Essa "dívida" era muitas vezes paga pela paciente por intermédio de sua participação como voluntária nas pesquisas do lugar. Entretanto, nesse "jogo" das relações entre o médico e a paciente, esta última não é apenas um agente passivo a servir de "cobaia" nas pesquisas, mas um participante ativo do processo, entendendo o papel que lhe cabe e disponibilizando seu corpo em favor das pesquisas, para que em troca continue sendo atendida nesse centro de referência em saúde da mulher.

\section{AGRADECIMENTOS}

Ao Conselho Nacional de Desenvolvimento Científico e Tecnológico (CNPq) pelo suporte financeiro da pesquisa, por meio do Edital 057/2008.

\section{NOTAS}

${ }^{1}$ Pesquisa desenvolvida em conformidade com a Resolução 196/96 do Conselho Nacional de Saúde sobre pesquisas envolvendo seres humanos. Conta com a aprovação do Comitê de Ética em Pesquisa da Faculdade de Ciências Médicas da Universidade Estadual de Campinas (Unicamp), parecer: 736/2009.

${ }^{2}$ A pesquisa é resultado da tese de doutorado de Rebeca Buzzo Feltrin (2012), sob orientação de Lea Velho, intitulada Entre o campo e o laboratório: a construção da menopausa dentro de um hospital-escola brasileiro, defendida em 2012 no Departamento de Política Científica e Tecnológica (IG/Unicamp).

${ }^{3}$ Nesta e nas demais citações de textos em outros idiomas, a tradução é livre.

${ }^{4} \mathrm{O}$ foco do Aism em prestar atendimento "integral" baseia-se na necessidade de dar assistência à saúde da mulher para além de sua fase reprodutiva, com auxílio de uma equipe multidisciplinar.

${ }^{5}$ A inscrição ou inscrição literária é definida por Latour e Woolgar (1997) como procedimentos de materialização do objeto de estudo em traços, gráficos, imagens etc., que permitirão interpretações e servirão como base para elaboração de enunciados científicos.

\section{REFERÊNCIAS}

BRASIL.

Projeto de Lei n.857, de 2009. Denomina

Professor Doutor José Aristodemo Pinotti, o Centro de Atenção Integral da Mulher - Caism. Brasília. 2009.

\section{CALLON, Michel.}

The role of the lay people in the production and dissemination of scientific knowledge. Science, Technology and Society, v.4, n.1, p.81-94. 1999.

COLLINS, Harry; PINCH, Trevor.

Dr. Golem: how to think about medicine.

Chicago: The University of Chicago Press. 2005.
CONRAD, Peter.

Medicalization and social control. Annual Review of Sociology, v.18, p.209-232. 1992.

FELTRIN, Rebeca Buzzo.

Entre o campo e o laboratório: a construção da menopausa dentro de um hospital-escola brasileiro. Tese (Doutorado) - Departamento de Política Científica e Tecnológica do Instituto de Geociências, Universidade Estadual de Campinas, Campinas. 2012.

FIGO.

International Federation of Gynecology and Obstetrics. Professor José Aristodemo Pinotti 
(1934-2009). 2009. Disponível em: http://www. figo.org/news/professor-jos\%C3\%A9-aristodemopinotti-1934-2009. Acesso em: 5 dez. 2011. 2009.

FOUCAULT, Michel.

Microfísica do poder. Rio de Janeiro: Edições Graal. 1979.

FOUCAULT, Michel.

Vigiar e punir: nascimento da prisão. Petrópolis: Vozes. 1977.

FOUCAULT, Michel; DELEUZE, Gilles.

Os intelectuais e o poder: conversa entre Michel Foucault e Gilles Deleuze. In: Foucault, Michel. Microfísica do poder. Rio de Janeiro: Edições Graal. p.69-78. 1979.

FREIRE, Letícia L.

Seguindo Bruno Latour: notas para uma antropologia simétrica. Comum, v.11, n.26, p.46-65. 2006.

GIERYN, Thomas F.

City as truth-spot: laboratories and field-sites in urban studies. Social Studies of Science, v.36, n.1, p.5-38. 2006.

GIERYN, Thomas F.

Three truth-spots. Journal of the History of the Behavioral Sciences, v.38, p.113-132. 2002.

GIERYN, Thomas F.

A space for place in sociology. Annual Review of Sociology, v.26, p.463-496. 2000.

HENKE, Christopher.

Making a place for science: the field trial. Social Studies of Science, v.30, p.483-511. 2000.

KOHLER, Robert E.

Place and practice in field biology. History of Science, v.40, p.189-210. 2002.

LATOUR, Bruno.

A esperança de Pandora: ensaios sobre a realidade dos estudos científicos. Bauru: Edusc. 2001.

LATOUR, Bruno.

Ciência em ação: como seguir cientistas e engenheiros sociedade afora. São Paulo: Unesp. 2000.

LATOUR, Bruno.

Give me a laboratory and I will raise the world. In: Knorr-Cetina, Karin D.; Mulkay, Michael J. (Org.). Science Observed. Beverly Hills: Sage. 1983.

LATOUR, Bruno; WOOLGAR, Steve.

Vida de laboratório: a produção dos fatos

científicos. Rio de Janeiro: Relume Dumará. 1997.

LOCK, Margaret.

Encounters with aging: mythologies of menopause in Japan and North America. Los Angeles: University of California Press. 1993.
OMS.

Organización Mundial de la Salud. Investigaciones sobre la menopausia en los años noventa. Serie de informes técnicos, n.866, p.1-15. Genève: OMS. 1996.

OSIS, Maria José D.

Paism: um marco na abordagem da saúde reprodutiva no Brasil. Cadernos de Saúde Pública, v.14, n.1, p.25-32. 1998.

OSIS, Maria José D.

Atenção Integral à Saúde da Mulher: o conceito e o programa, história de uma intervenção.

Dissertação (Mestrado) - Instituto de Filosofia e Ciências Humanas, Universidade Estadual de Campinas, Campinas. 1994.

PINOTTI, José A.

Currículo: José Aristodemo Pinotti. Disponível em: http://www.drpinotti.com.br/curriculo.htm. Acesso em: 5 dez. 2011. 2008.

RICE, Tom.

"Beautiful murmurs": stethoscopic listening and acoustic objectification. Senses \& Society, v.3, n.3, p.293-306. 2008.

ROZENFELD, Suely.

Terapia hormonal para a menopausa $(\mathrm{TH})$ : múltiplos interesses a considerar. Ciência \& Saúde Coletiva, v.12, n.2, p.437-442. 2007.

SHAPIN, Steven.

Here and everywhere: sociology of scientific knowledge. Annual Review of Sociology, v.21, p.289-321. 1995.

STRICKER, George; TRIERWEILER, Steven J. The local clinical scientist: a bridge between science and practice. American Psychologist, v.50, n.2, p.995-1002. 1995.

SUGIMOTO, Luiz.

Uma homenagem póstuma a Aristodemo Pinotti, que deu um sobrenome ao Caism. Disponível em: http://www.unicamp.br/unicamp/ divulgacao/2010/09/10/uma-homenagempostuma-a-aristodemo-pinotti-que-deu-umsobrenome-ao-caism. Acesso em: 10 out. 2011. 2010.

TRENCH, Belkis; SANTOS, Claudete G. Menopausa ou menopausas? Saúde e Sociedade, v.14, p.91-100. 2005.

VIGETA, Sonia M.G.; BRÊTAS, Ana Cristina P. A experiência da perimenopausa e pósmenopausa com mulheres que fazem uso ou não da terapia de reposição hormonal. In: Secretaria Especial de Políticas para as Mulheres. Redações e trabalhos científicos monográficos premiados no $2^{\circ}$ Prêmio Construindo a Igualdade de Gênero. Secretaria de Políticas para as Mulheres, Brasília. p.95-105. 2006. 